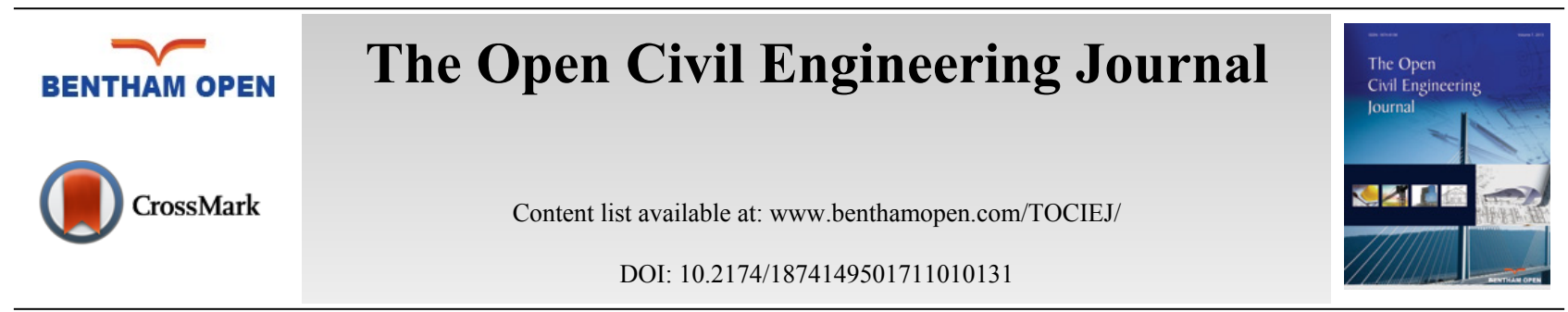

RESEARCH ARTICLE

\title{
Suspen-Dome System: A Fascinating Space Structure
}

\author{
IfeOlorun Olofin * and Ronggui Liu \\ Department of Civil Engineering, Jiangsu University, 301 Xuefu Road Zhenjiang, Jiangsu Province, China
}

\begin{abstract}
With the recent trend in long span space structures, suspen-dome as a roof structure is becoming popular. Therefore, as the construction of long span structures increases in the world today, the effectiveness of suspen-dome structure should be considered in order to undertake further development of the system which may be required to improve its design and construction. One direction of the improvement of such structures is to seek new materials other than using the traditional steel to yield better results. This paper is a review of the suspen-dome system, including its characteristics, its use in space construction, its success as well as the possibility of replacing steel with other materials for better results. From the review, it is found that using steel cables in suspen-dome structure has some shortcomings which can be eliminated by the use of other materials. It is suggested that Carbon Fibre Reinforced Polymer (CFRP) can be the material because of its advantages over steel as indicated in the paper.
\end{abstract}

Keywords: Space structures, Suspen-dome, Prestressing structures, Carbon fibre reinforced polymer cables, Projects.

\section{INTRODUCTION}

The space structure is truss-like, lightweight and rigid in nature. Generally, it is built from interlocking struts in a geometric pattern [1]. Recently, there has been an up surge of interest in space structures: lattice domes and tensegrity structures which are becoming widely used around the world. Long span space structures came into existence in the 1970s based on the discovery of new light-weight and high-strength materials such as steel, which are utilized to make structures better. Examples of space structures include beam string structures, cable domes, cable truss structures and suspen-domes, and so on. Structures with span longer than 20 metres could be regarded as long span structures and need to be carefully designed, which require to keep balance in all aspects: the weight, deflection and foundation forces.

This paper reviews a popular space structure type known as suspen-dome system that came into existence in the 1990s. The structure was developed by Japanese engineers, when a tensgrity (cable-strut) system was introduced to a single layer reticulated dome. The basic aspects of the suspen-dome system, including its structural characteristics, its practical application and how it differs from the other space structures such as the single layer dome and the cable dome, are presented in this paper. Recommendations are made by researches to create a more efficient structure.

\section{SUSPEN-DOME SYSTEM}

A suspen-dome is a long span roof structure which is very slender and lightweight [2]. It is a composite system of a single layer truss dome and a tensegric system (struts and cables). The roof is made up of a single layer reticulated shell (upper) and a tensegrity (cable-strut) system (lower) as shown in Fig. (1). The upper single layer latticed dome is fortified by the lower tensegrity system.

\footnotetext{
* Address correspondence to this author at the Department of Civil Engineering, Jiangsu University, 301 Xuefu Road Zhenjiang, Jiangsu Province, China; Tel: +86 18652726384; E-mail: epher2002@yahoo.com
} 


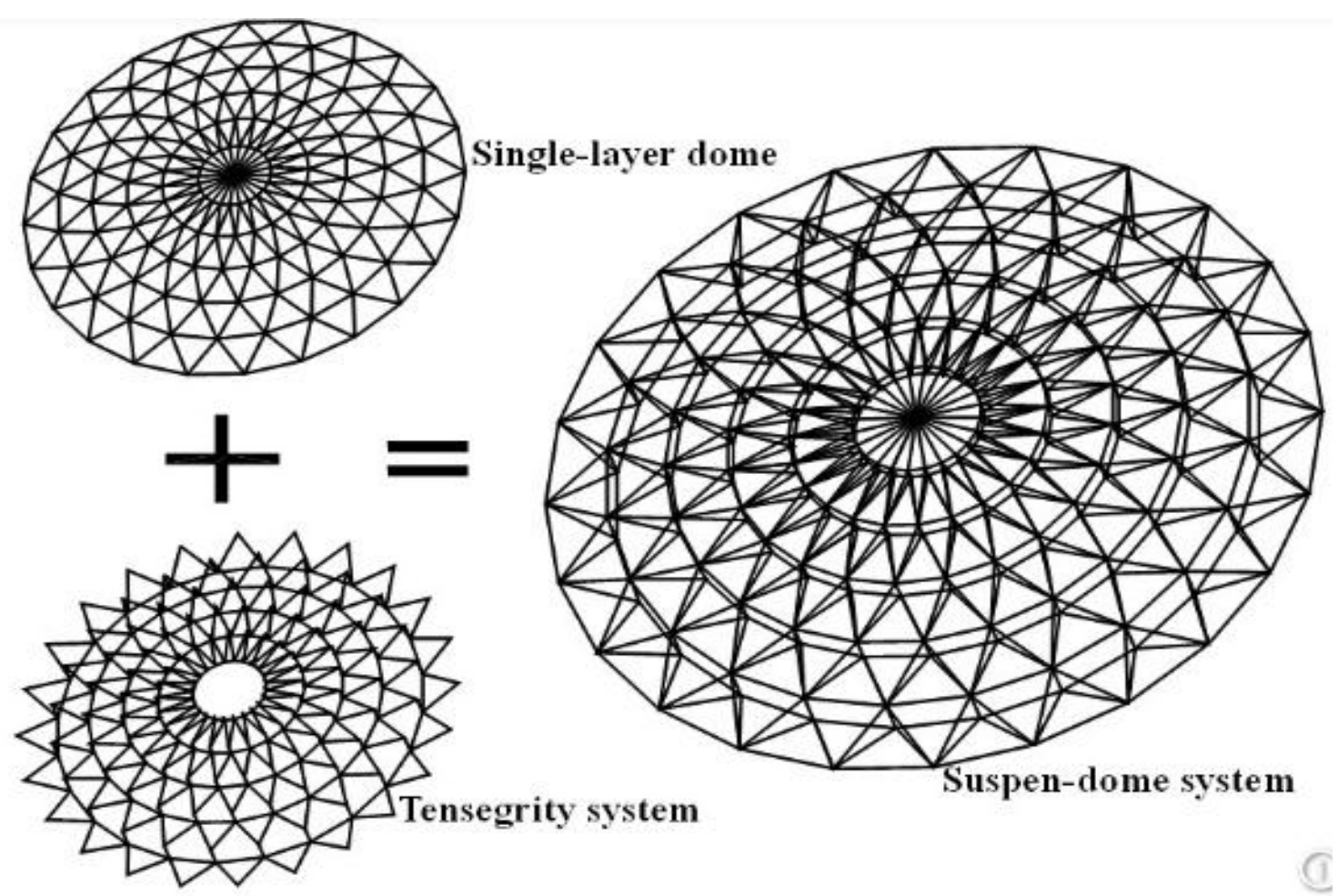

Fig. (1). Composition of a Suspen-dome system. "Kitipornchai et al. [2]".

The cable-struts system is made up of the radical cables, struts and hoop cables as shown in Fig. (2) and an outline drawing of the structural system is given in Fig. (3).

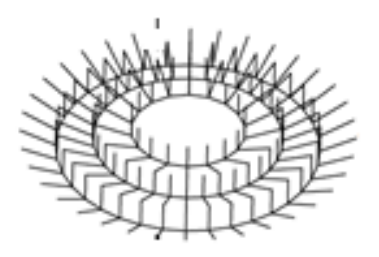

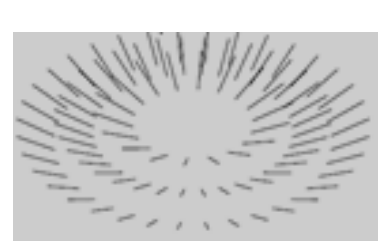

Radical cables

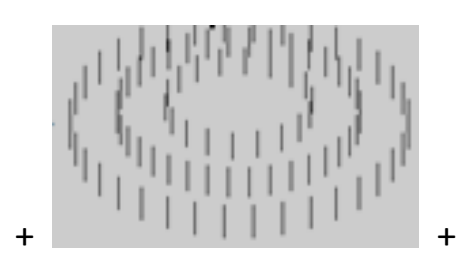

Struts

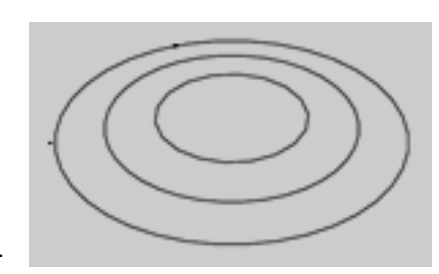

Hoop cables

Fig. (2). A Cable-strut system composition.

The suspen-dome technology combines the advantages of the lattice shell technique and those of the cable domes. The suspen-dome structure often displays some horizontal reactions which can be reduced through the careful arrangement of prestressing cables. This is because, according to Dong, et al. [3], prestressed cables can alter the values and distribution of stress in the structure, thereby increasing the stiffness of the structure. The most common plan of a suspen-dome is round, however, elliptical, polygonal and rectangular plans are also possible [3]. 


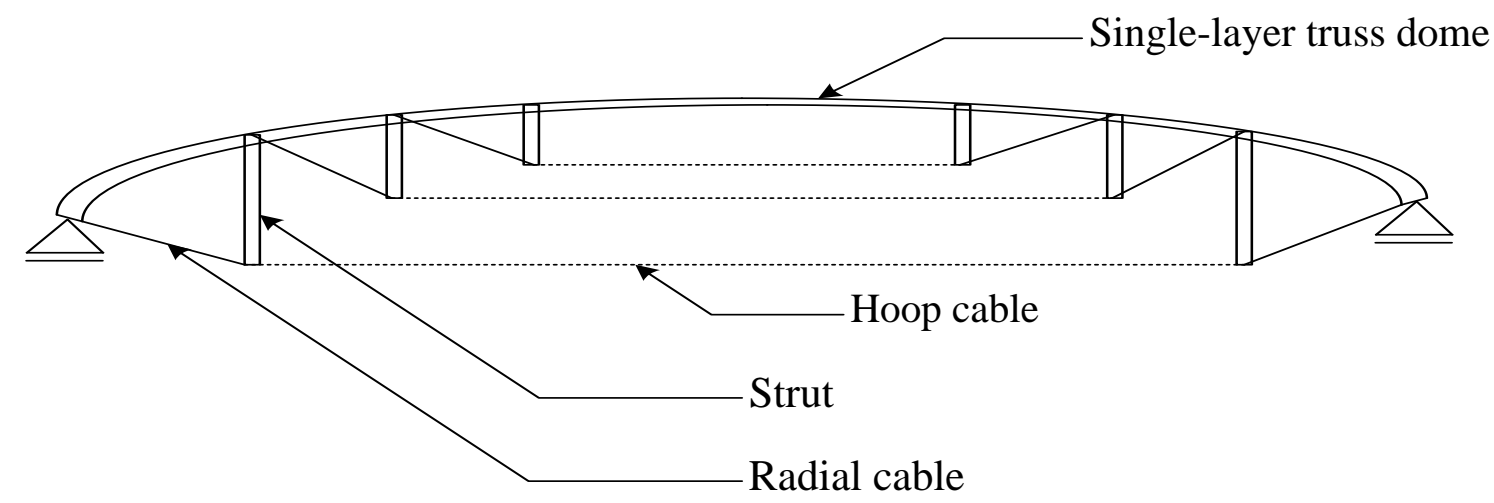

Fig. (3). Sectional view of a suspen-dome.

\subsection{Types of Round Suspen-Domes}

Suspen-domes can be classified into several types based on the characteristics of the upper structure and those of the lower cable bar system as illustrated in Fig. (4).
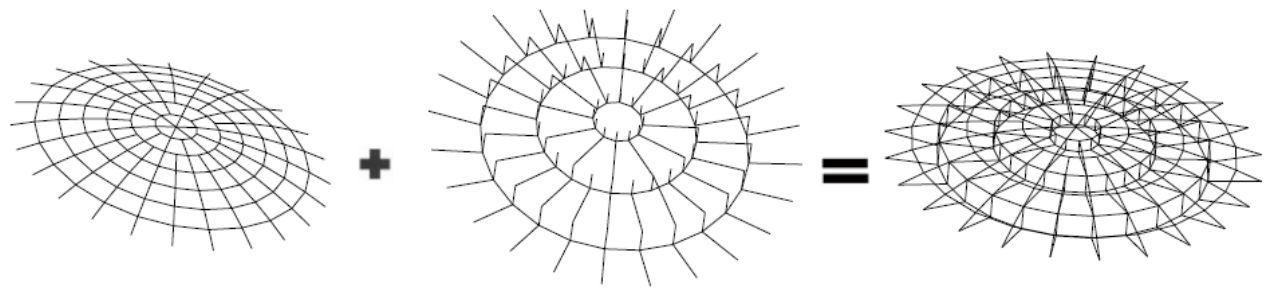

b) Sunflower suspen-dome
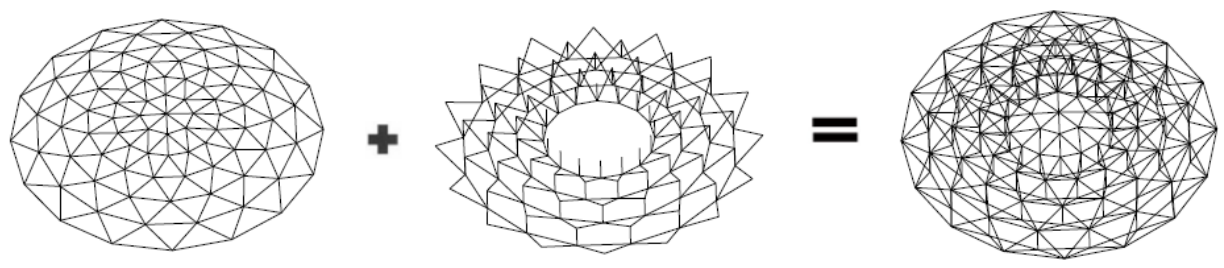

c) Kiewitt suspen-dome
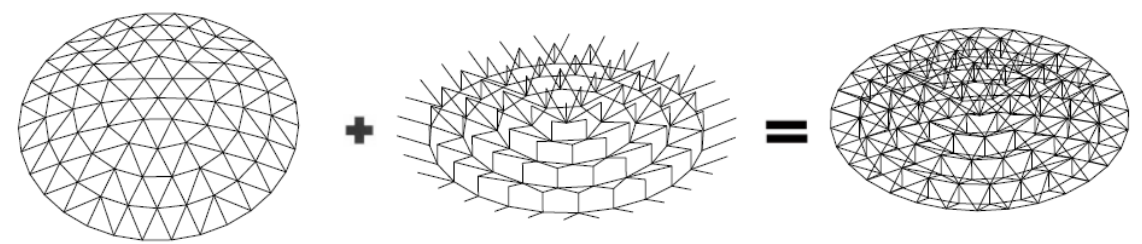

d) Bird nest suspen-dome
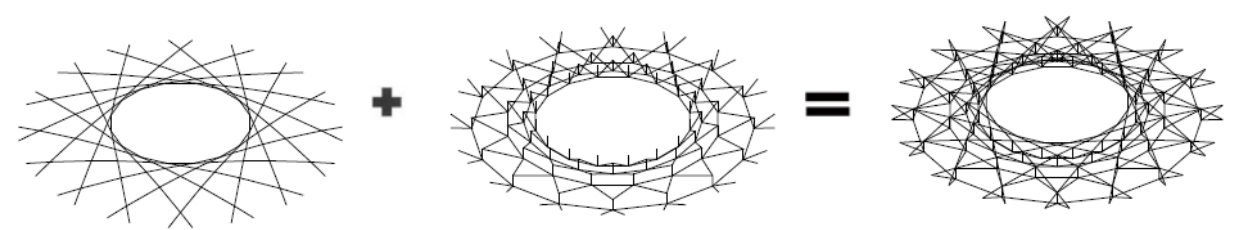

Fig. (4). Types of round suspen-domes. 
A suspen-dome structure system is characterized by controlling the stress and deformation through using the tensegric system. Excessive structural flexibility experienced in cable domes can be prevented and the strength of the single layer dome against buckling can be increased. The advantages of a suspen-dome include:

i. It reduces burden on the boundary structure.
ii. It increases strength against buckling.
iii. It controls structural flexibility.

\subsection{Characterstics of Suspen-Dome}

The characteristics of a suspen-dome can be illustrated as follows:

i. The ultimate bearing capacity of the structure is higher, since the upper and lower structure working together.

ii. A suspen-dome is a self-equilibrated system which is dependent on the design style.

iii. The construction of suspen-dome is more convenient compared to cable dome.

iv. Suspen-dome is made up of double radical cables which are stable and its application is practical.

\subsection{Prestressing Structures}

Suspen-dome systems are extremely efficient prestressing structures. The prestressing forces in the cable have a significant effect on the structural performance of the system. Suspen-domes consist of prestressed space grid structures. The system is a categorized hybrid system mainly due to its combination of bar element, beam element and cable element. By applying inverse force to the structure, it can improve the structural performance of the system by decreasing deformation [5]. However, on one hand, the prestressed force of the hoop and radical cables must be sufficiently large not to make the structure slacken. On the other hand, it must not be too large to make the struts buckle [2]. Of course, it is known that the suspen-dome design has one major problem that is the initial determination of the level of the prestress in the lower tensegrity system [6]. The application of prestressing is to improve the structural behavior of space grids and reduce the consumption of materials. Prestressed structures for long span structures are often dependable on the stability of presstressing forces.

\subsection{Equilibrium of Prestressing Forces}

Fig. (5) illustrates the plan view of a typical node which is connected to the strut at the ring of the suspen-dome structure which relate to 'Eq. $(2-4)$ '.

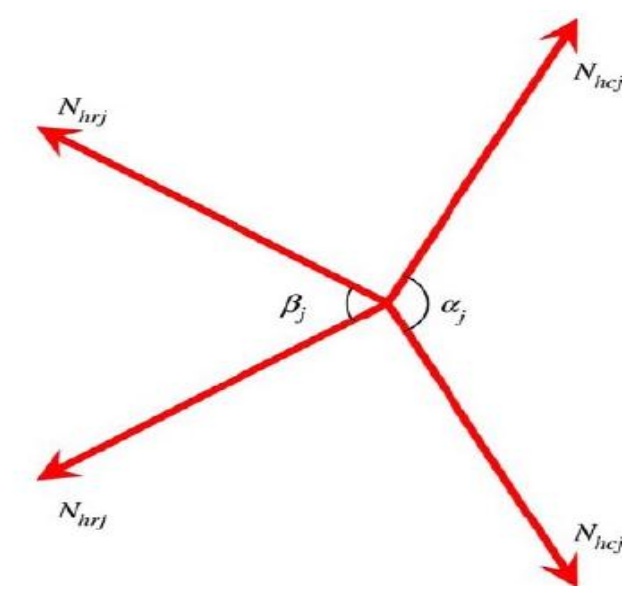

Fig. (5). Axial forces at equilibrium (Side view).

The axial equilibrium force in a given node $\mathrm{i}, \mathrm{N}_{\mathrm{hcj}}$ is the axial force in the hoop cable, $\mathrm{N}_{\mathrm{hrj}}=$ axial force in the radical cable, $N_{s}=$ axial force in the strut, $\alpha_{j}=$ the angle between the hoops and $\beta_{\mathrm{j}}=$ the angle between the radical cable and strut.

Following the principle of force balance in the strut and hoop direction, the equilibrium at any given node is: 


$$
\begin{gathered}
N_{s}=-N_{h r j} \cos \beta_{i} \\
N_{h r j} \sin \beta=2 N_{h c j} \cos \left(\frac{\alpha_{i}}{2}\right)
\end{gathered}
$$

The equilibrium at any given joint is given as

$$
N_{h r j} \cos \left(\frac{\beta_{i}}{2}\right)=N_{h c j} \cos \left(\frac{\alpha_{i}}{2}\right)
$$

To fulfill equilibrium conditions at nodes, every bar must be connected to at least three cables not in one plane or two cables in the case where bars and cables are in one plane.

The prestressing force of the cable can be determined by

i. Load imposed on structure

ii. Critical deflection

Eq. (4) is considered in obtaining prestressing forces imposed on the cables.

$$
N_{h c i}=N_{h c 1}\left[1-\frac{\sum_{j=1}^{j-1} d j}{\sum_{j=1}^{n} d j}\right]
$$

\section{HISTORY OF SUSPEN-DOME}

In 1993, the first suspen-dome in the world was created by Prof. Mamoru Kawaguchi and his team. This state of the art structure, known as the Hikarigaoka dome, was constructed in Japan. In China, one of the halls in the service business centre located in Tianjin represents the early edition of suspen-dome. Likewise, Changzhou gymnasium and Beijing polythenic gymnasium built in 2007 and 2008 respectively carried the suspen-dome system. The Jinan Olympic gymnasium with a span length of 122 metres was built in 2009 and it has been acclaimed as the world's longest span with suspen-dome (Fig. 6). One of the applications of the suspen-dome technology was its adoption in building the canopy for Shenzhen North railway station without any supporting column in 2010. In describing the structure, Dong et al. indicated that a two-way multi-span design was adopted whereby the lattice shell was a continuous cylinder "with a covering area of $68,000 \mathrm{~m}^{2}$ and a column grid of $28 \mathrm{~m} \times 43 \mathrm{~m}$, making it the first suspended cylindrical lattice shell with rectangular plan form in the world" [3]. The railway suspen-dome structure has become a very popular one especially in Asia because of its attractive mechanical properties [4]. Kitipornchai et al. [2] declared that "the suspendome system is one of the most attractive space structures due to its excellent structural properties." However, there are still many practical problems for the structure to be solved such as mechanics analysis, economical characteristics, difficulties in construction and so on. Researchers have carried out investigations to solve some of these challenges.

\section{PREVIOUS RESEARCHES}

Kitipornchai et al. [2] addressed several issues on the lamella suspen-dome structure. An efficient analysis method was presented to study the effect of cable prestress force and external loads on the structural behavior of the suspendome system; they also included parametric study of the structural characteristics and buckling capacities. Geometric imperfection, asymmetric loading, rise-to-span ratio and connection rigidity on the buckling capacity of the suspendome system were examined. Results obtained showed that the geometric imperfection plays an important role in the buckling capacity of the suspen-dome system; the buckling capacity of the system under full span and half span loading are not evidently different. The authors emphasized that the connection rigidity and rise-to-span ratio are important factors affecting the buckling capacity; as the pin-connected suspen-dome system had lower buckling capacity when the suspen-dome had a small rise-to-span ratio. 


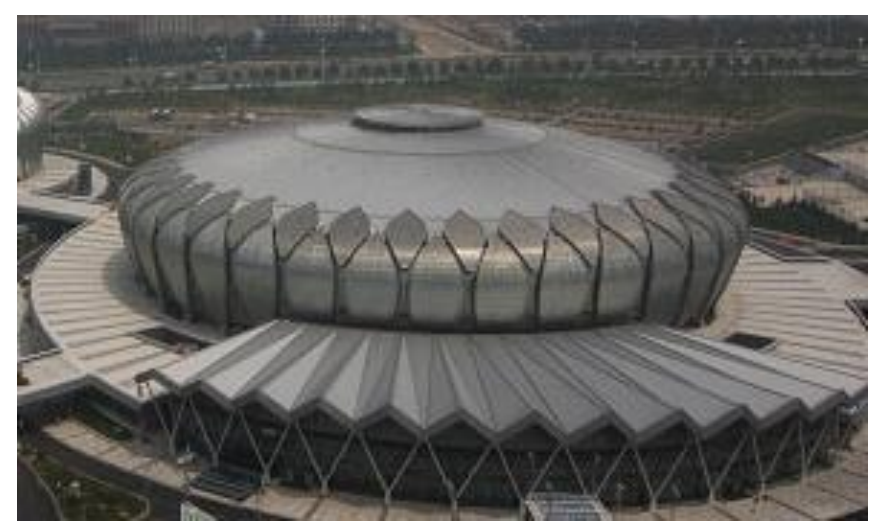

Fig. (6). The Jinan Olympic gymnasium.

Wenjiang et al. [4] divulge that tensegric system can greatly improve the mechanical properties of a single layer dome because it decreases nodal displacement by inversing load on the single layer steel truss which improves the buckling capacity of the system.

Zhi-Hong et al. [7] carried out a research on the structural design of a suspen-dome, using a high strength, seven steel wires as the cable properties with an elastic modulus of $1.90 \times 10^{5} \mathrm{~N} / \mathrm{mm}^{2}$. One of their conclusions was that for a large span structure such as the suspen-dome, the material strength and structural vertical deflection are governed by the design, and the design limitations should be based on the buckling strength of the structure.

Liu et al. [8] investigated a new type of continuous cable joint on a suspen-dome with a stacked arch. The cable joint was in two states, locked state and unlocked state. For the locked state the hoop cables could not slide around the cable joint, whereas for the unlocked state, the hoop cables slide around the cable joint. It was concluded that the stability behavior when the continuous cable joint is locked is better than that of the unlocked state.

The researchers Hongbo et al. [9] investigated the prestressing force deviation induced by sliding friction and temperature between the hoop cables and cable strut joints during the prestressing construction of a suspen-dome structure. Five advanced prestressing construction measurements were presented to reduce prestressing deviation. The measurements include increasing the prestressing joint, over prestressing the construction, adoption of rolling cablestrut joints, modification of prestressing construction control values that considered temperature change and selection of the hottest time for prestressing construction. The researches came to the conclusion that the experimental and numerical results from the construction measures could effectively reduce the prestressing deviation.

To study the mechanical properties of a suspen-dome structure with rolling cable joints, a 1: 10 scaled-down model of a suspen-dome, which was adopted in gymnasium in Shandong Province, was built by Chen et al. [10]. The rolling cable strut joints were applied to the suspen-dome to diminish the friction loss in the process of tensioning the cable and to guarantee the global stability of the structure. The experimental results indicated that the pretension of the outer circle of the cable has the greatest influence on the suspen-dome system and the pretension of the lower cables influences each other. Hence, they concluded that due to the introduction of the tensegrity system in the suspen-dome structure, the static performance of the suspen-dome structure is superior to that of the single layer reticular shell. Indeed, according to Li et al. [11], suspen-dome structures are more rigid and can resist greater external load because of their mechanical properties compared with those of cable domes. The authors also discussed the construction sequence simulation analysis of Jinan Olympic suspen-dome. The construction errors were simulated using random imperfection modal method. Using the integral structure model, the concrete supporting system was considered, the effects of the temperature variation on the suspen-dome were analyzed using ANSYS. The conclusion is that a low influence of temperature variation on the structure can be realized if the integral structure is modeled with a concrete supporting system. Little effect on the construction errors were obtained in the cable-bar element in respect to the mean axial internal force.

Furthermore, Mamoru et al. [12] developed a suspen-dome consisting of a single layer truss dome and a cable structure in order to carry out a structural test on the system. The model tested was circular with a diameter of 3 metres; brass pipes were employed for the single layer trusses whereas steel rods were used for the cable system. The results obtained by controlled loads showed that the axial stress in the dome members was smaller in the suspen-dome than in the single layer truss dome. Also, the buckling test illustrated that the suspen-dome had a buckling load of 1.5-1.8 times 
that of the single layer truss dome.

A nonlinear analysis was undertaken based on the effect of time integral by Zhong et al. [13] for a suspen-dome structure considering the temperature field distribution, displacement and stress. The results achieved showed that the structure has a better spatial work performance; the central of the structure is the weakest point and the reason for large deformation is due to reduction in stiffness and strength levels.

Similarly, Chen et al. [14] determined the effect of the elastic modulus and expansion co-efficient on a prestressed steel structure. The Tianbao Centre suspen-dome was the case study. An ANSYS Parametric Design Language was created to analyze the model. The result obtained indicated that the change in the cables expansion co-efficient and elastic modulus has a great effect on the performance of the suspen-dome. At high temperature, the expansion coefficient of the hoop and radical cables was large at maximum displacement and at low temperature. The elastic modulus of the hoop cables was large on the constrained support forces. The researchers concluded that it was necessary to give a precise linear expansion co-efficient and elastic modulus for different cables, since there are variations in values of the elastic modulus and expansion co-efficient of steel cables.

Also, Li et al. [15] investigated the structural stability of a suspen-dome by creating (computing) a kiewitt suspendome model of span $92 \mathrm{~m}$. The analysis of the load displacement of the structure was carried out by using NewtonRaphson and Arc length methods. Parameters that could affect the structural elastic plastic's ultimate carrying capacity such as the rise to span, height of struts and prestress of cables. Part of the authors' conclusion stated that improving the prestress aspect did not improve the ultimate load carrying capacity of the suspen-dome structure, whereas the higher rise to span ratio and height of the struts improved the ultimate loading carrying capacity of it.

The authors Zhang et al. [16] created a design procedure for a proposed sport centre located at Jinan city since no provisional design codes were provided for the suspen-dome system. ANSYS finite element software was used to analyze the structure, putting into consideration the self-internal-force and the prestress ratio among the three ring cables in order to verify the prestress in the cable. In addition, parameters such as the static, buckling, geometrical nonlinear buckling, modal, response spectrum, time history, wind induced effect and construction cable failure and node design were all analyzed. The researchers believed that results obtained from the study can be employed in designs and provide materials for revising certain design codes.

Bo-qing et al. [17] investigated the sensitivity of prestress cables in a suspen-dome system due to the fact that cable construction plays a vital role in erecting a suspen-dome system. A kiewitt suspen-dome was used as the case study. Static and dynamic behaviors and buckling load prestresses were considered in the cable. Conclusion drawn indicated that the suspen-dome system was sensitive to the prestresses in the entire cables of the structure; the sensitivity also depended on the location and the structural behavior of the cable.

Chen et al. [18] created a new kind of multi-node sliding cable element for a suspen-dome. A tangent stiffness matrix was derived and the multi-node sliding cable element was inputted in ABAQUS software for the analysis. Static and non-linear stability analyses of the dome under symmetric and asymmetric loads were undertaken. Conclusion drawn was that the sling of the latitudinal cables' uniform axial force distribution can be achieved for the tensegric system which can improve the material efficiency of the cable, and also can prevent the cable from sagging under asymmetrical loads. In addition, it was discovered that whether the latitudinal cable slides or not it has little effect on the static behavior and non-linear stability of the single layer lattice dome under asymmetrical loads.

Guo et al. [19] focused on the distribution and magnitude of initial geometrical imperfection during stability calculation, based on numerical models and different distribution of initial geometrical imperfection. The result showed that the stability factor was lower when the first antisymmetric buckling mode was developed. The initial geometrical imperfection distribution and magnitude ranges between $1 / 500$ and 1/300 of the structural span and the structural stiffness was low.

Guo et al. [20] investigated the static behavior of a suspen-dome under heaps load for both experimental and numerical findings. Such loads appear during construction or active service but prominent during construction. The authors created a 1:15 reduced scale of a suspen-dome model with an actual span of $122 \mathrm{~m}$. Heap loads of $80 \mathrm{~kg}$ in value were loaded at 5 different times during the study. Conclusion drawn includes that the overall structural stability factor under full span load is larger than the heap load. Stress and displacement distribution uniformity under heap load is worse than that of full span load. The findings showed that heap loads brought about disadvantatges in the structural static properties. 
The structural behaviors of a suspen-dome with stacked arch structures are very complex. Liu et al. [21] investigated the non uniform thermal behavior of the Chiping Gymnasium suspen-dome under summer solar radiation, the effect of the cable sliding friction and healing temperature were also considered. The analyzed results showed that solar radiation affects the structure, the behavior of the suspen-dome with non-sliding cable-strut joint is better than those with sliding cable-strut joints. Finally, the healing temperature of the upper arches and the lower suspen-dome affects the thermal response of the structure.

According to Liu et al. [22], prestressing loss due to sliding friction during prestressing constructions has an effect on the mechanical behavior of a suspen-dome under dead and live loads and the sliding friction co-efficient between the cable-strut joint and the hoop cables changes the structural behavior. The structural behavior is at its best when the sliding co-efficient is large enough to make the hoop cable not to slide around the joint and worst when the sliding friction co-efficient is zero.

The authors Liu and Chen [23] established a closed sliding polygonal cable element and analyzed the structural behavior of a cable dome and suspen-dome structure with sliding cable joints. They concluded that the sliding cable joint reduces the cable prestressing loss and a uniform inner force is obtained for the hoop cable.

To study the effect of friction between the cable-strut joint and the hoop cables in a pre-stressing construction of a suspen-dome, Liu et al. [24] carried out an analysis, using ANSYS Parametric Design Language based on a simplified method presenting a frozen-heated theory and large curvature assumption. The results showed that the method can effectively simulate the pre-stressing construction process and that sliding friction can be calculated by non-curvature and curvature assumption which makes a significant effect on the pre-stressing construction. In addition, the friction coefficient number for the pre-stressing joint and pre-tensioning control value has a great influence on prestressed construction.

Numerical investigation was carried by Liu et al. [25] to determine the effect of temperature change during construction of a suspen-dome structure. The authors concluded that the temperature change during construction has an effect on the prestressing construction. The error between the practical prestressing force and design prestressing force was stipulated to be about $212 \%$ based on temperature changes during construction. A simplified calculation formula was developed and verified to calculate the control value of prestressing construction under temperature changes.

Zhou et al. [26] developed a novel form analysis method, considering the influence of pretension process for a suspen-dome. An iterative method was presented for modal analysis and a sequential analysis method was proposed for the pretension process simulation. The combination of the two methods gave a form method for a pretension process to be constructed for a suspen-dome. Two examples were carried out to verify the proposed method. The numerical example showed that both the error of the nodal co-ordinate and cable force converged to a set of stable tolerance. The engineering example showed that without considering the influence of pretensioned process, the form analysis would be an error and the final state of cable tension deviates from the expected initial state. With the authors proposed method accurate results can be achieved.

Zhou et al. [27] focused on the effect of geometric imperfection of members based on nonlinear geometrical buckling and seismic performance of a suspen-dome. Using Changzhou gymnasium as a case study and implementing ANSYS for its simulation, three numerical examples were employed to validate the imperfect elements. Results show that the imperfection value has a great influence on the structural stiffness, the initial state responses are different, and the seismic displacement increases while the stress in the rods and cables decreases.

\section{PREVIOUS RECOMMENDATIONS}

Previous researches showed that suspen-dome system has better performance under different load combinations compared with cable dome and single layer dome. Its light weight and appropriate performance are advantages of suspen-domes. The following are the recommendations made by previous researchers who worked on the structure.

i. Building rigid connections is very tedious compared with pin connections which are recommended for suspendome structures due to the buckling effect when the span is large [2].

ii. The rise of span ratio should be small, for a suspen-dome, preferably within a range less than 0.15 [2].

iii. An efficient method for studying suspen-dome system under various load condition is called superposition analysis. This method allows engineer to determine the relationship of member stress in the cable force and external load; it also generates required cable prestress forces needed to prevent cables from slacking under 
different load conditions [2].

iv. Further research should be carried out to improve both the structural stress and bulking capacities as the long span dome grows rapidly [4].

v. A multi stage fabrication scheme should be employed to reduce construction cost. The inverse analysis method was suggested for the construction sequence simulation analysis of the suspen-dome when a single-stage fabrication scheme was required [11].

vi. Heap loads should be considered in the design of the structure and measures should be taken to avoid such loads during construction [20].

vii. A Cable-strut joint with small friction co-efficient should be considered for future design of a suspen-dome [24].

\section{AUTHORS' PROPOSAL}

With the vast development in long span structures, steel is popularly used due to its high strength and light weight properties. From the reviewed articles the material employed for the analysis, design and construction of the system were made up of steel for both the reticulated shell and the tensegrity system of the structural system. From the reviews, it is clear that using steel cables for suspen-dome structure has some problems which can be settled by the use of other materials. The material that can substitute steel in cable system is Carbon Fibre Reinforced Polymer (CFRP) due to its physical properties in terms of low thermal expansion coefficient, low density and high tensile strength. The question arises: why not replace steel cables with carbon fibre reinforced polymer cables? Researches mentioned below have proven that such cables achieve better quality performance. Some advantages of CFRP cables over steel were discovered [28] even though the modulus of elasticity for CFRP is lower to that of steel. The density of CFRP is $1 / 5$ compared to steel's density and the ultimate tensile strength is about twice as high as steel [29]. Several researches indicate that CFRP has the advantage of fatigue and corrosion resistance when properly installed [30]. In 1996 in Winterthur, Switzerland, a cable stayed pylon bridge of $124 \mathrm{~m}$ length was built where CFRP stay cables were applied experimentally for the first time [31]. Wen et al. [32] carried out a study on six cabled stayed bridges with main span length of $1400 \mathrm{~m}$. The results show that CFRP stay cables tend to reduce the global stiffness of bridges, but the decrease is insignificant and acceptable in engineering practice. Recently in China, Mei analyzed and designed a CFRP cable stayed pedestrian bridge in Southeast University [33]. The structure was erected in Jiangsu University, Zhenjiang in 2005 which is the first cable-stayed bridge to be constructed with CFRP cables in China [34]. Reinforcement measures with CFRP sheets has been applied to Ibach Bridge near Lucerne in Switzerland since 1991 [35]. Since then CFRP products have been used in reinforcing, strengthening, prestressing structures and also as cables in cable systems. Fire resistance is another problem of CFRP cables. Decomposition of CFRP materials occurs when exposed to elevated temperature conditions [36] and CFRP loses its strength and stiffness, which will result in failure [37]. However, precautionary measures against fire should be considered in the design of CFRP cable system. Methods of protection against fire include spraying a fire resistant coating on the surface of CFRP cables or by increasing the fire resistance of CFRP itself, which is the essential method to avoid CFRP exposure to fire. This can be achieved by adding nanoclay into CFRP polymer resin to increase the fire resistance significantly [36]. These are issues that would need to be resolved. Notwithstanding these difficulties, it appears that carbon fiber is a kind of important engineering materials that is worthy of popular application

\section{SUBSTITUTING CFRP FOR STEEL}

In substituting CFRP cables for steel in suspen-dome structure construction, it will be necessary to consider the anchoring, fire resistance of the cables and to identify the best areas of application.

\subsection{Anchoring CFRP Cables}

The key problem facing the application of CFRP cables and restricting the development of their widespread use in the future is how to anchor them. However, the anchorage system worked by EMPA laboratory solved the problem by the use of a truncated cone-shaped locking block filled with casting material, the mechanical properties change in accordance with the length of anchorage [31]. From previous researches anchoring would not be necessary for a suspendome; the cable pulley system can be adopted for the cable system.

\subsection{Existing Challenges and Proposed Application}

In spite of the advantages of CFRP over steel and its other qualities, there are some problems of the materials cited above which require solutions before their wide application. Consequently, there is the need for more research on CFRP 
cables compared with that of steel in terms of the life span, fire resistance and other current challenges. Solution to these problems will make the application of CFRP cables in a suspen-dome a state of the art phenomenon.

The tensegritic system which is made up of the struts, hoop cables and radical cables is cable system. Generally, a high level of prestress is salient for achieving high stiffness in structures. CFRP cables could be used as pre-stressing materials due to their high strength. The advantages of CFRP over steel as pre-stressing material are light weight and corrosion resistance. With the non corrosive nature of CFRP cables compared to steel, the non-corroding durability of such structures will last for many years. Although CFRP is an expensive material, the safety and life service of structures are paramount. Despite the desirable features of CFRP cables, their applications in a space structure are scarce. However, Olofin and Liu investigated the modal behavior of a small model suspen-dome with CFRP tensegrity system by means of numerical analysis, in order to grasp the actual performance of the suspen-dome [38]. The results of the analysis showed that CFRP cables have several desirable traits which can be exploited in the design and construction of a tensegrity system. Similarly, Ye et al. [39] investigated two orthogonally loaded cable structures-the spoked wheel cable roof and a cable net façade with CFRP and compared with that of steel counterparts. Results showed that CFRP cables can effectively enhance the mechanical and economical behavior of orthogonally loaded cable structures.

\section{CONCLUSION}

With the advantageous properties of CFRP, it is necessary to investigate if CFRP is a feasible cable material for long span space structures such as a suspen-dome. Positive results would indicate that it is necessary to use carbon fibre reinforced polymer cables in place of the traditional steel cables for the construction of suspen-dome system. With the revolution of composite material predicted in 1960 it has evolved into this century. Indeed, knowing that composite material is the future of the construction of long span structures, researches on the engineering application of CFRP into the construction of suspen-dome structures are necessary owning to the fact that long span structures are on the increase. In addition, factors such as the efficiency and effectiveness of CFRP cables can be determined and the need for their application in other civil engineering structures can be ascertained.

\section{CONFLICT OF INTEREST}

The authors confirm that this article content has no conflict of interest.

\section{ACKNOWLEDGEMENTS}

The authors acknowledge the support of the National Science Foundation of China (Grant no: 51608234) and Province Science of Jiangsu: BK20160534.

\section{REFERENCES}

[1] N. Subramanian, Space Structures: Principles and Practice., Multi-Science Publishing Co Ltd, 2006.

[2] S. Kitipornchai, W. Kang, H. Fai Lam, and F. Albermani, "Factor affecting the design and construction of Lamella suspen-dome system", J. Construct. Steel Res., vol. 61, no. 6, pp. 764-785, 2005. [http://dx.doi.org/10.1016/j.jcsr.2004.12.007]

[3] S. Dong, Y. Zhao, and D. Xing, "Application and development of modern long-span structures in China", Front. Struct. Civ. Eng., vol. 6, no. 3, pp. 224-239, 2012.

[4] W. Kang, Z. Chen, H. Lam, and C. Zuo, "Analysis and design of the general and outmost ring stiffened suspen-dome structure", Eng. Struct., vol. 25 , no. 13 , pp. 1685-1695, 2003. [http://dx.doi.org/10.1016/S0141-0296(03)00149-4]

[5] B. Shirkhanghah, A. Darabadi-Zare, H. Eimani-Kalesa, and B. Pahleran, "Investigation into behavior of suspen-domes in comparison with single-layer domes", World Acad. Sci. Eng. Technol., vol. 6, no. 9, pp. 745-752, 2012.

[6] Q. Cao, and Z. Zhang, "A simplified strategy for force finding analysis of suspen-domes", Eng. Struct., vol. 32, no. 1, pp. 306-318, 2010. [http://dx.doi.org/10.1016/j.engstruct.2009.09.017]

[7] Z. Zhang, Q. Cao, S.L. Dong, and X. Fu, "Structural design of a practical suspen-dome", Adv. Steel Constr., vol. 4, no. 4, pp. 323-340, 2008.

[8] H. Liu, and Z. Chen, "Influence of cable sliding on the stability of suspen-dome with slacked arches structures", Adv. Steel Constr., vol. 8, no. 1, pp. 54-70, 2012.

[9] H. Liu, Q. Han, Z. Chen, X. Wang, R. Yan, and B. Zhao, "Precision control method for prestressing construction of suspen-dome structures", Adv. Steel Constr., vol. 10, no. 4, pp. 404-425, 2014. 
[10] Z. Chen, Y. Renzhang, W. Xiaodun, L. Hongbo, and X. Xiao, "Experimental researches on suspen-dome structure with rolling cable-strut joint", Adv. Steel Constr., vol. 11, no. 1, pp. 15-38, 2015.

[11] Z. Li, Z. Zhang, S. Dong, and X. Fu, "Construction sequence simulation of a practical suspen-dome in Jinan Olympic centre", Adv. Steel Constr., vol. 8, no. 1, pp. 38-53, 2012.

[12] M. Kawaguchi, M. Abe, T. Hatabo, I. Latemichi, S. Fujiwara, H. Matsufuji, H. Yoshida, and Y. Ama, "Structural tests on the system dome system", In: Proceeding of IASS-ASCE International Symposium, Atlanta, Georgia, USA, 1994, pp. 383-392.

[13] Z. Zhongling, H. Yongfu, and L. Shige, "Analysis of the fire resistance of a suspen-dome structure", Appl. Mech. Mater., vol. 166-169, pp. 1040-1044, 2012.

[http://dx.doi.org/10.4028/www.scientific.net/AMM.166-169.1040]

[14] Z.H. Chen, G.J. Sun, and Z.S. Liu, "The effect of cable material characteristic on suspen-dome", Adv. Mat. Res., vol. 156-157, pp. 1251-1255, 2010 .

[http://dx.doi.org/10.4028/www.scientific.net/AMR.156-157.1251]

[15] L. Feng, N. Jian, and D.L. Ran, "Investigation into the elastic plastic ultimate load carrying capacity of suspen-dome, Progress in Structure Pts1-4", Appl. Mech. Mater., vol. 166-169, pp. 1108-1112, 2012. [http://dx.doi.org/10.4028/www.scientific.net/AMM.166-169.1108]

[16] Z.H. Zhang, Q.S. Cao, X.Y. Fu, and S.L. Dong, "Structural design of the large span suspen-dome", In: Proceeding of International Symposium on Computational Mechanic, Hongkong, Macau, China, 2009, pp. 270-270.

[17] B.Q. Gao, and E.H. Weng, "Sensitivity analyses of cables to suspen-dome structural system", J. Zhejiang Univ. Sci., vol. 5, no. 9, pp. 1045-1052, 2004. [http://dx.doi.org/10.1631/jzus.2004.1045] [PMID: 15322998]

[18] Z.H. Chen, Y.J. Wu, Y. Yin, and C. Shan, "Formulation and application of multi-node sliding cable element for the analysis of Suspen-Dome structures", Finite Elem. Anal. Des., vol. 46, no. 9, pp. 743-750, 2010.

[http://dx.doi.org/10.1016/j.finel.2010.04.003]

[19] J.M. Guo, "Research on distribution and magnitude of initial geometrical imperfection affecting stability of suspen-dome", Adv. Steel Constr., vol. 7, no. 4, pp. 344-358, 2011.

[20] J.M. Guo, S.L. Dong, and X.F. Yuan, "Research on static property of suspen-dome structure under heap load", Adv. Steel Constr., vol. 8, no. 2, pp. 137-152, 2012.

[21] H.B. Liu, and Z.H. Chen, "Non-uniform thermal behaviour of suspen-dome with stacked arch structures", Adv. Struct. Eng., vol. 16, no. 6, pp. 1001-1009, 2013.

[http://dx.doi.org/10.1260/1369-4332.16.6.1001]

[22] H.B. Liu, and Z.H. Chen, "Research on effect of sliding between hoop cable and cable-strut joint on behavior of suspen-dome structures", Adv. Steel Constr., vol. 8, no. 4, pp. 359-365, 2012.

[23] H.B. Liu, and Z.H. Chen, "Structural behavior of the suspen-dome structures and the cable dome structures with sliding cable joints", Struct. Eng. Mech., vol. 43, no. 1, pp. 53-70, 2012. [http://dx.doi.org/10.12989/sem.2012.43.1.053]

[24] H.B. Liu, Z.H. Chen, and X.D. Wang, "Simulation of pre-Stressing construction of suspen-dome considering sliding friction based large curvature assumption", Adv. Sci. Lett., vol. 4, pp. 2713-2718, 2011. [http://dx.doi.org/10.1166/asl.2011.1716]

[25] H.B. Liu, Z.H. Chen, and T. Zhou, "Research on the process of pre-stressing construction of suspen-dome considering temperature effect", Adv. Struct. Eng., vol. 15, no. 3, pp. 489-493, 2012.

[http://dx.doi.org/10.1260/1369-4332.15.3.489]

[26] Z. Zhou, F. Yu-Long, M. Shao-Ping, and J. Wu, "A novel form analysis method considering pretension process for suspen-dome structures", KSCE J. Civ. Eng., vol. 18, no. 5, pp. 1411-1420, 2014. [http://dx.doi.org/10.1007/s12205-014-0111-4]

[27] Z. Zhou, J. Wu, and S. Meng, "Influence of member geometric imperfection on geometrically nonlinear buckling and seismic performance of suspen-dome structures", Int. J. Struct. Stab. Dyn., vol. 14, no. 3, 2014. [http://dx.doi.org/10.1142/S0219455413500703]

[28] K. Mei, and Z. Lu, "Static characteristic analysis of CFRP cables", China J. Highw. Transp., vol. 17, no. 2, pp. 43-45, 2004.

[29] X. Zhang, and L. Ying, "Aerodynamic stability of cable-supported bridges using CFRP cables", J. Zhejiang Univ. Sci. A, vol. 8, no. 5, pp. 693-698, 2007. [http://dx.doi.org/10.1631/jzus.2007.A0693]

[30] S. Adanur, A. Mosallam, M. Shinozuka, and L. Gumusel, "A comparative study on static and dynamic responses of FRP composites and steel suspension bridges", J. Reinf. Plast. Compos., vol. 30, no. 15, pp. 1265-1279, 2011. [http://dx.doi.org/10.1177/0731684411418391]

[31] K. Flaga, "Advance in material applied in civil engineering", J. Mater. Process. Technol., vol. 106, pp. 1-3, 2000. 
[32] X. Wen, C.S. Cai, Y. Zhang, and R. Xiao, "Study of super long span cable stayed bridges with CFRP components", Eng. Struct., vol. 33, no. 2, pp. 330-343, 2011. [http://dx.doi.org/10.1016/j.engstruct.2010.10.013]

[33] K. Mei, "Study on Cable Stayed Bridges with CFRP Cables", Phd dissertation, Southeast University, Nanjing, China, 2005.

[34] K. Mei, Y. Li, and L.Z. Lu, "Application study on the first cable-stayed bridge with CFRP cables in China", J. Traffic Transp. Eng., vol. 2, pp. 242-248, 2015. [English Edition].

[35] U. Meier, "Carbon fibre-reinforced polymers: modern materials in bridge engineering", Struct. Eng. Int., vol. 2, pp. 7-12, 1992. [http://dx.doi.org/10.2749/101686692780617020]

[36] G. Ji, G. Li, and W. Alaywan, "A new fire resistant FRP for externally bonded concrete repair", Construct. Build. Mater., vol. 42, pp. 87-96, 2013 [http://dx.doi.org/10.1016/j.conbuildmat.2013.01.008]

[37] C. Lopez, J.P. Firmo, J.R. Correia, and C. Tiago, "Fire protection systems for reinforced concrete slab strengthened with CFRP laminates", Construct. Build. Mater., vol. 47, pp. 324-333, 2013.

[http://dx.doi.org/10.1016/j.conbuildmat.2013.05.019]

[38] I. Olofin, and R. Liu, "Numerical modal analysis of a suspen-dome with carbon fibre reinforced polymer tensegrity system", ASME J. Ser. Modell. A, vol. 89, pp. 13-24, 2015.

[39] Y. Liu, B. Zwingmann, and M. Schlaich, "Advantages of using CFRP cables in orthogonally loaded cable structures", AIMS Mater. Sci., vol. 3, no. 3, pp. 862-880, 2016.

[http://dx.doi.org/10.3934/matersci.2016.3.862]

(C) 2017 Olofin and Liu

This is an open access article distributed under the terms of the Creative Commons Attribution 4.0 International Public License (CC-BY 4.0), a copy of which is available at: https://creativecommons.org/licenses/by/4.0/legalcode. This license permits unrestricted use, distribution, and reproduction in any medium, provided the original author and source are credited. 